\title{
Transition from Linear to Circular
}

\section{Economy}

Sugam Upadhayay, DBA student

S.Upadhayay.177@westcliff.edu

Omaima Alqassimi, DBA student

O.Alqassimi.110@westcliff.edu

\begin{abstract}
The contemporary model of economical production and consumption is not sustainable; if the pattern continues, humankind will need to scramble for resources. Currently, resource extraction from the earth is 1.7 times higher than her actual capacity (Watts, 2018). This paper stresses the importance of the shift from the current linear (take, make and dispose) modality to a circular (take, make and reutilize) model to maximize the value from a product by keeping it in the loop of circularity. In pursuit of this change in model, reverse logistics, performance economy, and sharing economy all need to be integrated in order to facilitate regenerative and restorative techniques which enable reusing, recycling, remanufacturing and refurbishing of resources. Businesses need to redesign and restructure their current processes so that they can reduce the consumption of resources, thus developing a competitive edge. Incineration and dumping of resources should be the last option. The assets that are able to sense, record and communicate information are referred to as "intelligent assets" which innovates "smart solutions" to enable a circular economy (MacArthur, 2016). But this paradigm shift is not possible alone through the effort of a single entity. Involvement and commitments from individual, regional, governmental and intragovernmental levels are mandatory as it helps to create a synergist effect.
\end{abstract}




\section{INTRODUCTION}

Society has always welcomed productivity since it has not only rewarded the producers with economies of scale but has also made buyers wealthier with consumer surplus. But a question remains, is this the golden rule of production and consumption or the best model for sustainable use of resources where equilibrium is obtained between the factors of production and its proportionate utility entailing the unequivocal saving of resources for upcoming progeny? The clandestine decay of resources that is jeopardizing the ecosystem is in process. Every segment of an economy including service, manufacturing and agriculture is epitomizing productivity to satiate their voracious quench for remaining competitive. Sadly, they are unable to manifest the opulence of sustainability. The problem is not with societal progress, but with the approach, which is detrimental and devastating to the environment (Sandoval, Garcia, \& Goenaga, 2016).

As per a report published by the United Nations, primary resource extraction which was comprised of roughly 22 billion tons in 1970, included materials such as fossil fuel, metals, and timbers. This ballooned to roughly 70 billion tons in 2010. If the rate continues in this pattern, there will be 180 billion tons of material needed annually by 2050 (Mosbergen, 2016). The commodity price rose by $150 \%$ from 2002 to 2010, making the real price decline of the previous 100 years disappear ("Towards the circular," 2014). Regrettably, the oscillation is coming back to us, the tiny particles from cars, power plants, waste incineration, and other sources are killing over 3 million people worldwide each year (Vaughan, 2016), and the estimated annual global health cost due to air pollution is currently over \$5 trillion (Stone, 2017).
The wealthiest countries resource rapaciousness is ten times more on average than that of poorer countries. As stated in the UN Environment report of 2010, North America and Europe had an annual per capital material footprint of 25 and 20 tons, whereas it is 9 for Asia Pacific (Mosbergen, 2016). The unequal global distribution of resources has intensified conflicting trade behavior among countries, thus creating a "dumping economy." The paradigm shift of the radical transformation of product development, process re-engineering, and selling and distribution along with responsible consumption and disposal is required for sustainability and the longevity of resources. The revision of backward and forward linkage to implement the green approach is a necessity. Thus, the time has come to draw a line between earning and caring and between vanity and insanity, where every government, business entity, and individual has to be active in the transition from the linear to circular model of production and consumption.

\section{LINEAR ECONOMY}

A linear economy is a business model that focuses on the take, make and dispose philosophy. Resources are extracted from the earth and then products are manufactured for consumption. The residuals of this consumption later accumulate in a landfill or are incinerated. Atrociously, only $14 \%$ of plastic is recycled annually, and if this continues, by 2050 , there will be more plastic than fish in the oceans. Once plastic gets into the waterways, it brings $\$ 13$ billion in annual losses to tourism, shipping, and the fishing industries (Kaplan, 2016). The plastic is just an example of the negative external consequences that we are dealing with due to linearity. There are thousands of such culprits, such as aluminum, steel, papers, cans, 
leathers, oils, and fossil fuels. Miserably, the unhealthy competition among the corporations has reduced product life cycles, making products obsolete and has converted them into waste, collapsing the ecological balance. Figure 1, seen below, depicts the flow of resources in a linear economy where the resources are ultimately trashed or dumped in the landfills.

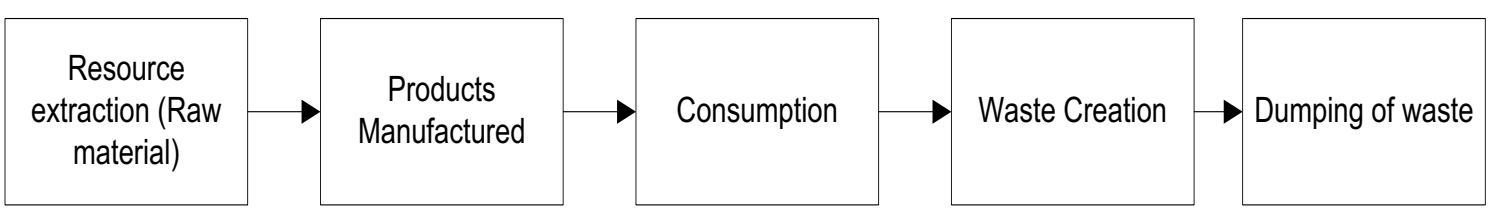

Figure 1. Linear economy flow diagram.

Although aware of the negative impact, businesses still thrive with this production methodology due to the low cost of raw material created by the competition and fewer mandatory regulation and legal penalties.

\section{Circular ECONOMY}

The circular economy advocates the shift from the traditional extract-produce-dispose economy to a restorative and regenerative approach where the focus is on extending the life cycle of a product to get the maximum value from it. The circular economy turns goods that are at the end of a life cycle into alternative resources, ultimately closing the loop in the industrial ecosystem and minimizing waste. Its philosophy builds on reuse, recycle, repair and remanufacture. The economic advantage of this model lies in the appropriate use of the waste, thus promoting performance economy, favoring resource productivity, and concentrating on escalating nature's capital and its resilience (Webster, 2017). Figure 2 illustrates the flow of resources in circular model of production and consumption.

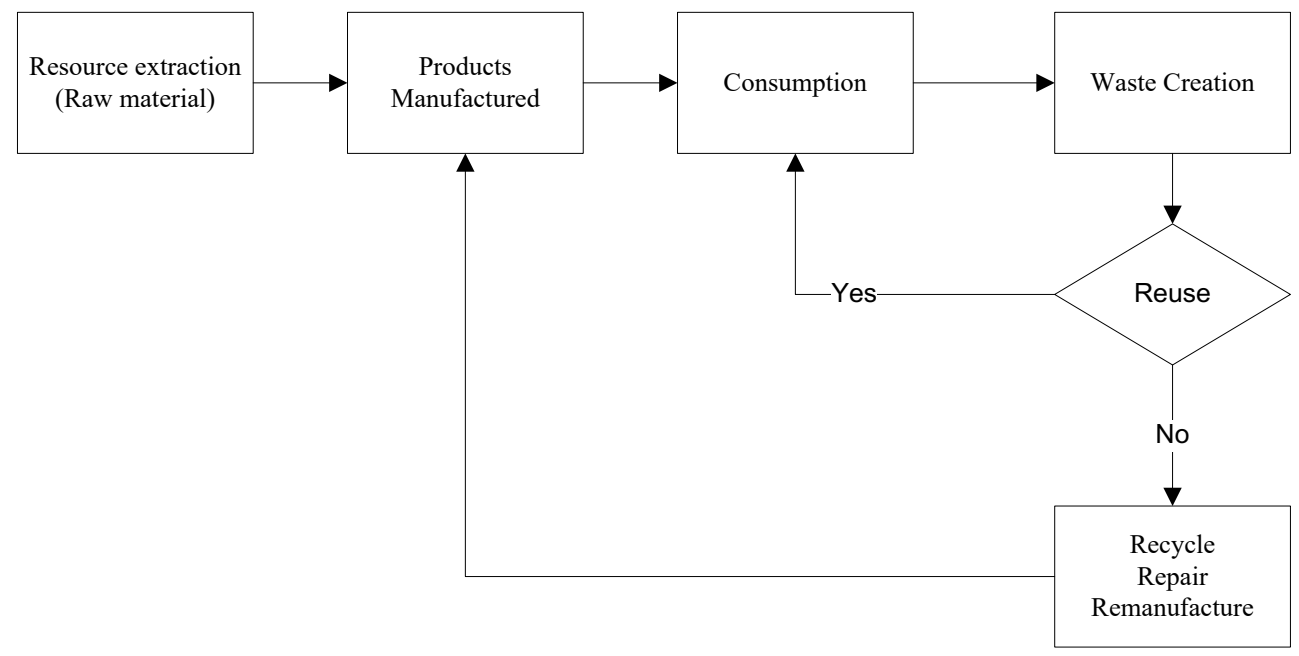

Figure 2. Circular economy flow diagram.

Maximum prioritization is given to make the resources transmit back into the 
production loop. Focus is on reuse, recycle, refurbish and remanufacture, rather than dumping.

\section{Understanding the Circular Model}

IDEO, a global design company, who crafted the first computer mouse for Apple, has collaborated with the Ellen MacArthur Foundation to strategize the best modules to use for a circular economy. The butterfly diagram as shown in Figure 3, which encapsulates the biological and technical cycle of resource utilization, is a feedback read system. The biological cycle comprises of biological materials like textiles, fruits, and foods that could be regenerated into the circular loop. The technical cycles are restorative. Both mentioned cycles advocate for reuse, refurbishing, remanufacturing and recycling of the products to the highest level possible. In the biological cycle, non-toxic products that are beneficial to the environment are returned to the biosphere directly or in the cascade of a series of uses.

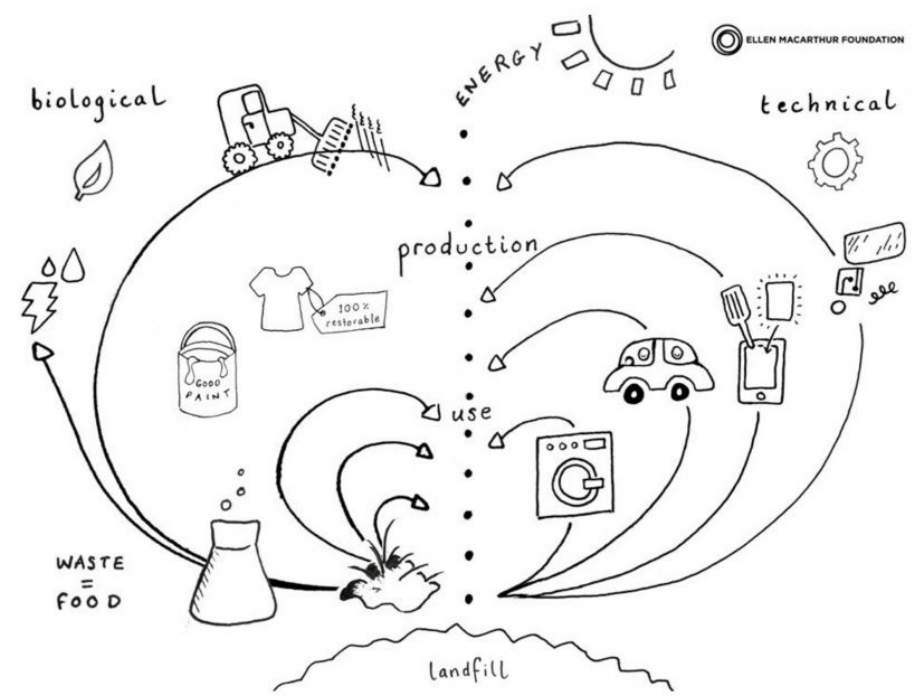

Figure 3. Butterfly diagram. (“Understand circular flows," 2014).

The circular model encourages businesses and individuals to be more mindful of environmental issues. Alternatives to wasteful packaging and fuel costs have been found through companies such as Ecovative and Lufa Farms. Ecovative has created reusable packaging from unused parts of plants (Ecovative, 2018), and Lufa Farms encourages rooftop gardens and hydroponic farming (Adam, 2015). Both concepts can be reconciled with the left side of the butterfly diagram where there is a focus on prolonging the value and life of raw materials used.

The right side of the butterfly diagram exemplifies the circular modality in technical products. It is restorative, where both the product and material would retain their integrity and highest utility. Examples of this can be seen by companies such as Zipcar. Rather than selling a new car, Zipcar rents unused ones. Additionally, according to the Environmental Protection Agency (EPA) in the USA, in 2012 alone, 84\% of unwanted clothes were trashed in a landfill or incinerated. Patagonia, a global apparel brand, focused on refurbishing the clothes so that they could be reused, and their value could be extended (Wicker, 2016). These types of small changes may not seem like a lot, but if all businesses started to use the circular economy model, 
great changes could be made in decreasing environment footprints.

\section{Principles of CirCULAR ECONOMY}

Sandoval, Garcia, and Goenaga (2016) in their extensive study of literature related to the circular economy prioritizes regenerative posture and the eco-centric perspective as a major principle within the circular economy. The circular economy is based on 3Rs, i.e., reduction, reuse and recycle. Stahel (2018) outlined the set of principles which guide the circular economy: (i) the smaller circulation of resources will make it profitable and resource efficient; (ii) the loops of material are circular and continuous in economy and feed into a new production process, minimizing the potential waste; (iii) maintaining value, performance and quality of goods; (iv) the efficiency in managing the stocks in circular economy is inversely related with the flow speed; (v) extending ownership is a costefficient strategy (vi) requirement of wellfunctioning second-hand market (Milios, 2018). Similar principles were emphasized by $\mathrm{FICCl}$, in the "Circular Economy Symposium 2018" held in India, to implement the idea of circularity into a business model. These concepts were identified as circular supply chain, recovery and recycling, product life extension, sharing platform, and selling products as a service. Out of the numerous factors that conceptualize a circular economy, the most crucial are listed below.

\section{REVERSE LOGISTICS}

Reverse logistics refers to the flow of goods and services from the point of consumption to the point of consolidation. It focuses on the backward flow of post-consumed resources which aim at closing the loopholes within a circular economy. Reverse logistics leads resources to the stages of remanufacturing, refurbishing, reusing or recycling, ultimately increasing the value of the resources. To utilize this concept, companies should consider the modality of reverse logistics at the time of product design to help in streamlining the work and alleviating unexpected future financial burdens. At the same time, the cost of reserve logistics could be the biggest challenge when compared to the residual value of goods. In California alone, 6000 computers become surplus a day and recycling cost between $\$ 15$ to $\$ 35$ for each monitor alone (Baltzan, 2014). Reserve logistics can be intricate when compared to forward logistics and must be considered previous to its development and implementation.

The research executed by KMPG (2017) emphasizes that the use of technology and infrastructure can reduce the lead time between production and getting the resources back. The barriers to reverse logistics are geographical dispersion, material complexity, and linear lock-in. As shown in Figure 4, the traditional approach of reverse logistics has significantly larger intermediaries when compared to the strategic approach. The diagram below clarifies the traditional and strategic approach to reverse logistics.

Efficient and effective handling of reverse logistics is a must. A new business initiative can fit the concept of reverse logistics and circular economy from the very first phase of the product and process design making the flow 


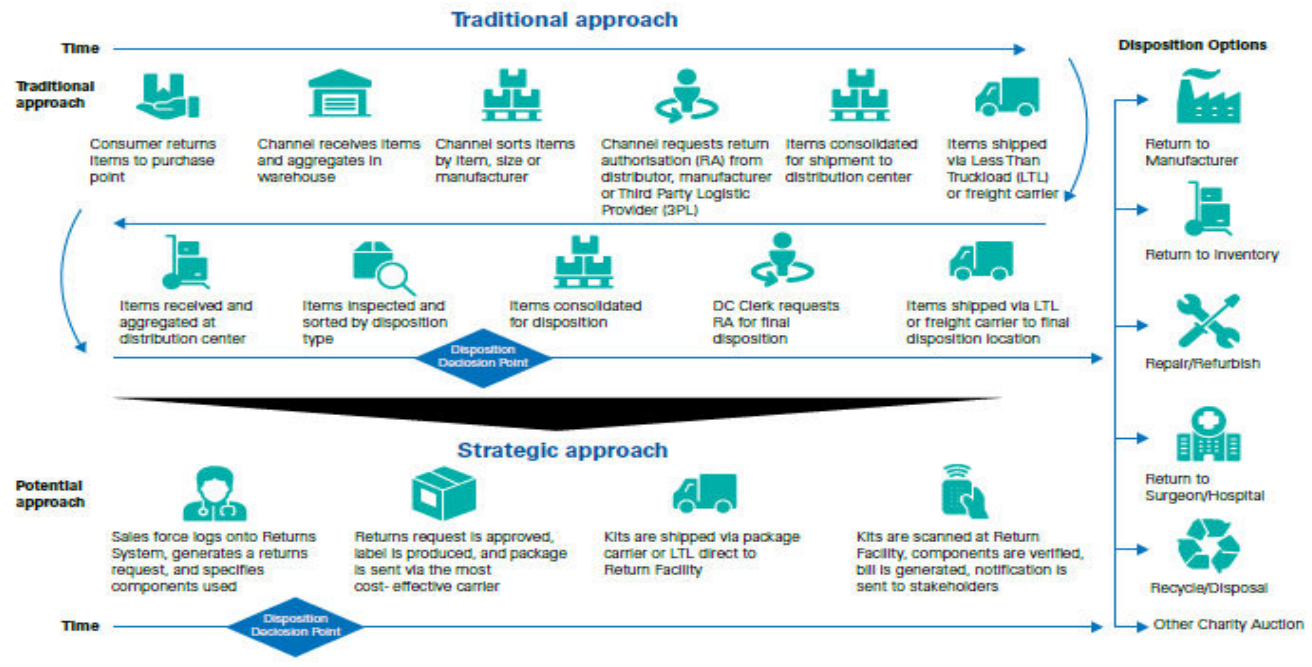

Figure 4. Traditional verses strategic logistic. (“Future-proof your reverse logistics,” 2017, p. 11).

seamless. The product design phase should focus on the listed parameters to ensure that the product lifecycle favors reverse logistics:

- Material Selection: material should be chosen in a way that the byproducts or scraps can be utilized again in future

- Standardized components: the consistent components support easy categorization and favors easy manufacturing

- Design to last products: the durability helps in saving resources and making products durable

- Design for easy end-of-life sorting: facilitates dismantling, separation and support in the reverse logistics of products

\section{Performance Economy}

The paradigm shift from the traditional to performance economy has had significant ramifications on the traditional business model. There have been changes from volume driven to value drive, energy and resource intensive to knowledge-intensive and from a linear to circular system (Stahel, 2010). Stakeholders are now more focused on smart solutions through smart products which are based on the minimum level of resource utilization.
The performance economy focuses on the service of its products. It is a paradigm shift from ownership to access economy. The customer becomes the user of the products rather than the owner of the products. Now, business models are based on an agreement to pay for use, lease, rent, and performance agreement through servitization (FICCl, 2018).

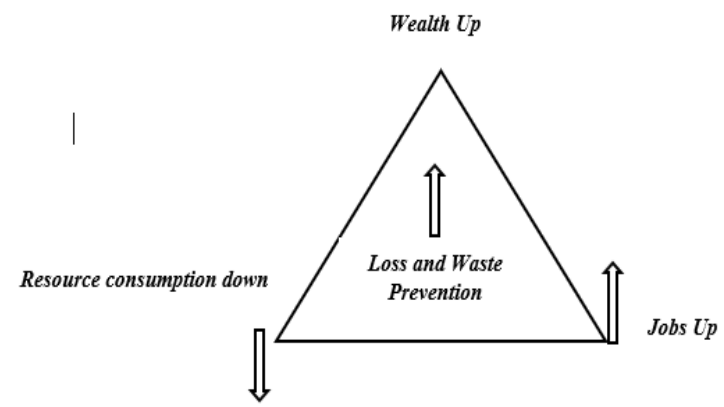

Figure 5. The objective of selling performance economy.

Examples of this can be seen with businesses such as Michelin Solutions, a USbased tire company, rather than selling their tires, lease them (Stahel, 2010, p.122) and YCloset, a China based apparel company, which leases apparel (Colao, 2012). As shown in Figure 5, both companies are practicing performance models of circular economies 
which has helped to maximize wealth, lower resource consumption, create jobs and prevent loss and waste of resources (Stahel, 2010). Amalgamation of performance economy will make high-end washing machines accessible to most households.

\section{SHARING ECONOMY}

The sharing economy has revolutionized the consumption of products and services. It is based on the philosophy of sharing excess resources and has empowered ordinary people to use their excess capacity rather than keeping it (Stemler, 2017). Botsman (2015) tried to bring clarity to the muddied concept of sharing economy by stating that it is the economic system where unused assets or services are used directly from individuals. Examples of this include Airbnb and BlaBlaCar. The facilitation of the sharing economy for the circular economy is seen where customers are served through existing excess products and services rather than by the production of new ones (Egerton, 2016).

The World Economic Forum (2016) has listed economic rebalancing, material efficiency, technological changes and highspeed domestic adoptions as reasons to adopt a sharing economy. The sharing economy, which was estimated to have generated over $\$ 229$ billion in 2015 , is projected to grow by $40 \%$ p.a. over the next five-years (World Economic Forum, 2016). This will bring tremendous economic, social and environmental benefits. Table 1, below, shows the various types of facilities being used in a sharing economy for each different kind of industry.
Table 1.

Various models of sharing economy with their examples.

\begin{tabular}{|l|l|}
\hline Types & Examples \\
\hline Peer-to-Peer Lending & Lending Club, Prosper, SoFi \\
\hline Crowdfunding & Kickstarter, Indiegogo \\
\hline Apartment/House Renting & Airbnb, Couchsurfing \\
\hline Ridesharing and Carsharing & Uber, Lyft, Car2Go, Zipcar \\
\hline Coworking & Share the cost of office rent, utilities \\
\hline Reselling and Trading & Craigslist, eBay \\
\hline
\end{tabular}

FACilitating AND IMPLEMENTING A CiRCUlaR ECONOMY

Investment in the circular model brings a win-win situation for producers as well as for consumers. It brings a positive impact in the economic, societal and environmental domain of society. As per Sandoval, Garcia, and Goenaga (2016), circular economy promotes innovation, decreases the pace of global resource depletion, and reduces the overuse of natural resources. Corporations should follow a circular model as it has become an aspect of corporate social responsibility (CSR). Implementation of the circular model favors symbiosis which helps corporations to reuse their products and fosters developing ancillary industries. Further government regulation plays a crucial role in making a circular philosophy a reality. The factors mentioned below induces and facilitates the circular economic model.

\section{Circularity as Corporate Social Responsibility (CSR)}

Resource stewardship has become a part of CSR. Incorporating circularity into the operational and corporate strategies of businesses will bring radical shifts in the production and consumption of goods and services. Envisioning and practicing circularity will represent the entity fulfilling their corporate social responsibility (CSR). It will provide a competitive and comparative advantage to each company utilizing it. 
Examples of this can be seen by companies such as IKEA who is collecting and reselling its previously sold products. In 2017, Google LLC diverted $91 \%$ of waste from the global data center operations away from landfills. These steps have not only economized the operation of the companies but has also unequivocally enhanced their image and reputation as they were able to reduce their environmental footprints. Circularity supports optimization of resource consumption and the extension of material life. It not only economizes the expenses and resource cost for a company, but also enhances the brand equity.

\section{GOVERNMENT LEVEL INITIATIVES}

The circular economy initiatives should not be voluntary or discretionary. Strong policies, laws, regulations, and initiatives from governmental and global arenas are deemed necessary to protect the environment and the way businesses function within it. Since 2009, the number of climate change laws has increased from 300 to 500 , carbon pricing was introduced, and 20 countries in Europe levied landfill taxes.

Regulation plays a binding role in manifesting circular economy. The European Union (EU) directives on circular economy includes the EU Action Plan, which has both mandatory legislation and voluntary measures included. The inability of the corporations to comply to the mandatory measures results in economic, administrative or criminal penalties, whereas the voluntary measures are not binding. As per Milios (2018), the policy measure should focus on the following factors so that corporations will abide and work within the principle of a circular economy.

\section{DURABILITY, REPARABILITY AND REMANUFACTURING POLICIES}

The durable product lasts for a long time, is easily repaired, and has available and accessible spare parts to support prompt product maintenance. This helps to extend the use of the product. Corporations should focus on product and process designs to make it durable and easy to repair so that the value and the life of the products increases, ultimately leading to decreased pressure on the natural resources needed to manufacture a new product.

\section{STRENGTHENING THE SECONDARY RESOURCE MARKET}

Clear policies should be in place to facilitate the secondary market, which includes the national or cross-border movement of used products. The developed secondary market facilitates the reserve logistic of the products after its end use, which could later be recycled, reused, remanufactured or refurbished.

\section{POLICIES PROMOTING AND HARMONIZING EXTENDED PRODUCER RESPONSIBILITY (EPR)}

Often there is a minimal incentive for a producer to innovate and design eco-friendly products. If the mechanism of reverse logistic is developed well, which supports the collection of the product back to the producer, third parties could reap the end benefits. For example, the scrapped electronic appliances are often collected and traded by third parties, thus disincentivizing the original producer from investing in the circular model. So, a corporation as well the regulators should have clear policy in place on ERP, which will encourage producers to invest in the circular model.

\section{SYMBIOSIS}

Symbiosis is the process where the end output from one activity is again used as a resource for another cycle so that the life cycle of the product is prolonged. Companies' generated waste is not only an environmental problem, but it is also an economic loss for the companies. The waste output of a company 
could be a valuable input resource for another company. Symbiosis, through regenerative and restorative techniques, could be used to prolong the life of the material.

An exemplary initiative in the circularity model can be seen in Srinivasan's Garbage to
Gold initiative (Drolia, 2016). The process illustrated in Figure 6 is a perfect apotheosis of symbiosis at the most rudimentary level where biomimicry can be observed.

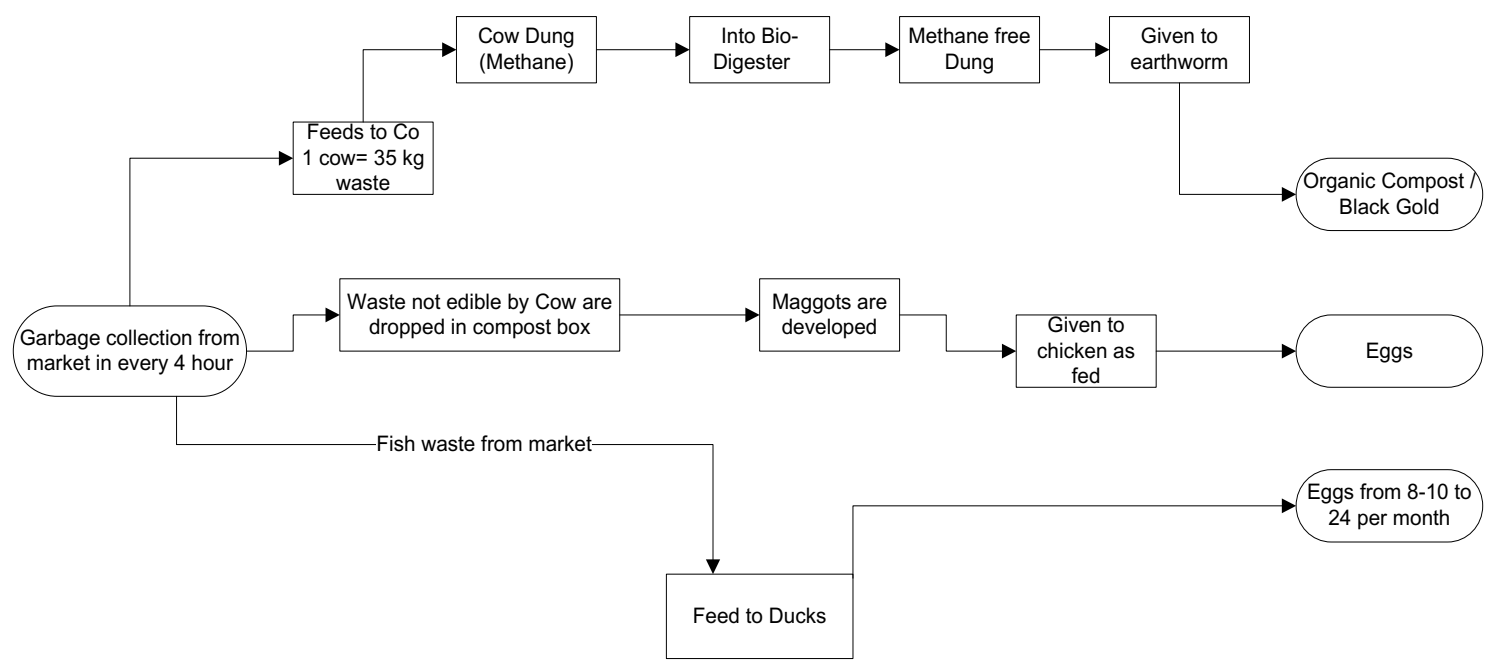

Figure 6. Flowchart showing symbiosis using the natural cycle.

In this process, no form of technology, artificial catalyst, or artificial feeds are used. The waste from a vegetable market, rather than ending up in a landfill, are used as the feed for cow, fish, hen and duck, ultimately generating energy and organic compost as an output. Corporations can use the modality of symbiosis in the same way. For example, old disposed batteries, rather than being dumped in a landfill, could be collected and recycled for future use. The waste water coming from industries after treatment can be used for irrigation. The plastic and metal waste should not be allowed to be disposed of haphazardly, but rather, should be collected for further use. These steps help in looping back the resources into the production cycle which extends their life and enhances their utility.

\section{Using TeChnology to LeVerage Circularity}

Technology creates interconnectedness, which facilitates the circular economy. For example, the use of radio frequency identification (RFID) makes tracking and collection of products easier, which supports reverse logistics. All the factors mentioned above, like sharing and performance economy along with symbiosis are supported by technology. Botsman (2013) has emphasized the capacity of technology to create an efficient platform where millions of haves are matched with millions of wants. By 2020, 2550 billion devices will be connected in the loop created by the Internet of things (IoT) which would create a trillion-dollar economy.

The breakthrough and commencement of the fourth industrial revolution is seeing advancements in technology like artificial intelligence (Al), augmentation reality, blockchain technology, and machine learnings. This has unlocked enormous potential in the circular model. Corporations embedding technological innovation to their product and process design can outperform resource utilization. "Liam" robot used by Apple to disassemble iPhones has collected 61 million 
pounds of reusable materials which includes 22,204 pounds of gold (Lacy, 2017).

The Internet of things (IOT) has given birth to "intelligent asset." Figure 7 shows how the scanner (asset) is remotely assessed by the producer and how maintenance is carried out as per the requirement leading to increase the life of the scanner.

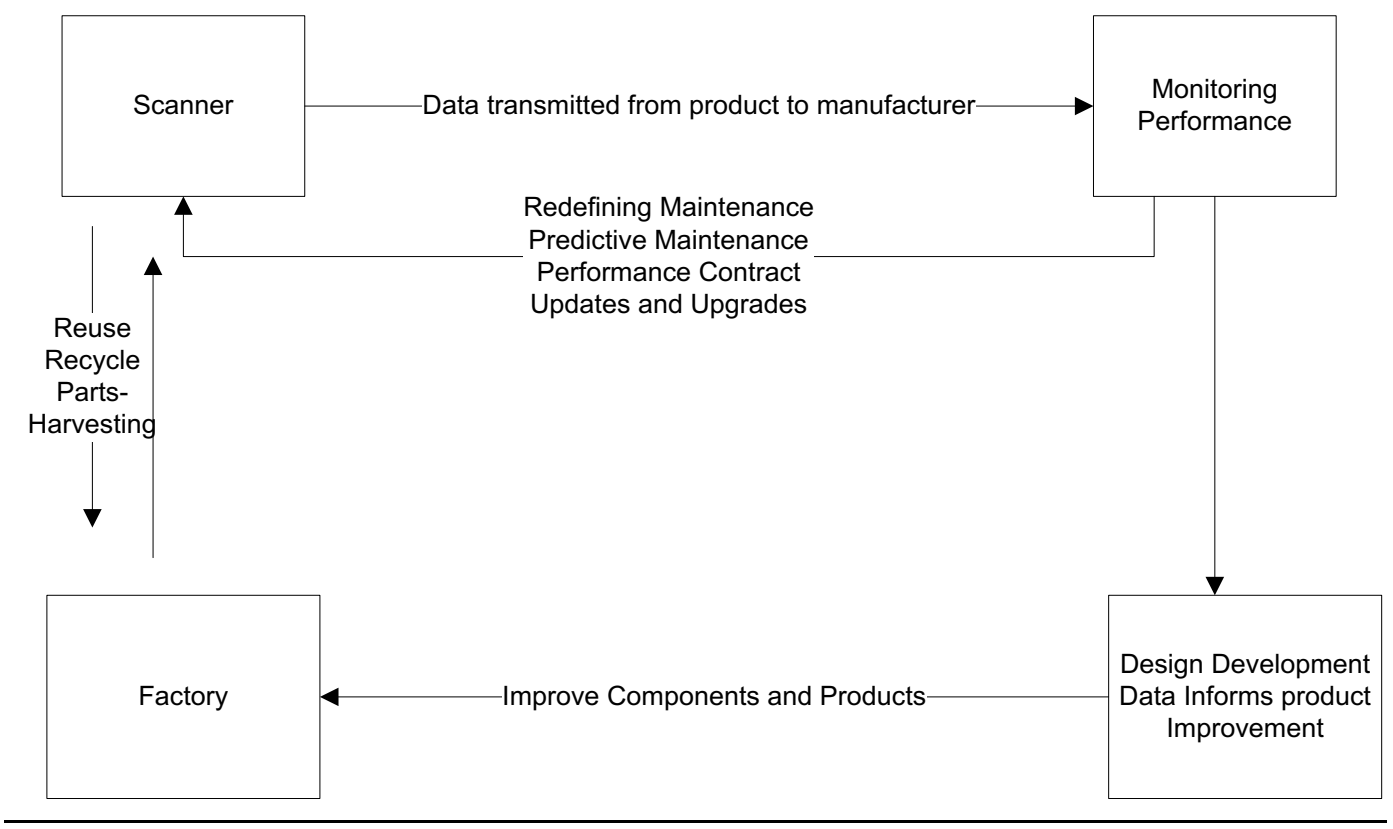

Figure 7. Intelligent Asset Transfer of data for circular economy. (“Intelligent assets: Unlocking the circular economy potential” 2016, p. 38).

Rather than selling the scanner to the user, the manufacture has rented it. The user will pay on a pay per use basis. At the end, the product will go back to the manufacture for recycling. It has facilitated the performance and sharing economy.

\section{AWARENESS OF CirCULAR ECONOMY}

With all of the advantages of a circular economy, it is phenomenal that there is still a majority of people who do not know about this concept (Guo, Geng, Sterr, Zhu, \& Liu, 2017). Governments, business entities, NGOs and INGOs all have a responsibility to collaborate and make the public aware of this style of economy. Some ways in which this can be done are as follows:

- Governments can incorporate the concept of the circular economy into academic courses. This will help younger generations to understand the very basics of circularity and its importance.

- Intermediaries like suppliers and retailers can also incorporate the circular model of production in their forward and backward linkage

- NGOs should focus on community and local institutional awareness programs. INGOs can play a pivotal role in the capacity building of stakeholders.

\section{ConClusions}

Shifting the production and consumption pattern from a linear to circular economy is unequivocally important to reduce the pressure in the extraction of resources from the environment. The circular economy through reverse logistic, performance and sharing economy helps in reusing, recycling, refurbishing and remanufacturing products 
which otherwise would have been thrown into landfills or incinerated.

Sadly, the clarity about the circular economy is still muddied. Awareness in local, regional as well as at the global arena is needed to move the circular economy into the mainstream economy. Corporations should embed circular philosophy into their product and process design from the very beginning. Additionally, the government should provide incentives and regulations to facilitate the implementation of a circular economy so that collectively we can work towards sustainability. 


\section{REFERENCES}

Adam, A. (2015, March 24). Lufa Farms takes gardening to a whole new level. Retrieved from www.globalnews.ca: https://globalnews.ca/news/1901306/lufa-farms-takes-gardening-to-a-whole-new-level/

Baltzan, P. (2014). Business Driven Information System (4th ed.). New York: McGrawHill.

Botsman, R. (2013, November 21). The sharing economy lacks a shared definition. Retrieved from www.fastcompany.com: https://www.fastcompany.com/3022028/the-sharing-economy-lacks-a-shareddefinition

Botsman, R. (2015, May 27). Defining the sharing economy: What is collaborative consumption-and what isn't?

Colao, J. J. (2012, October 11). Welcome to the new millennial economy: Goodbye ownership, hello access. Retrieved from www.forbes.com: https://www.forbes.com/sites/jjcolao/2012/10/11/welcome-to-the-newmillennial-economy-goodbye-ownership-hello-access/\#56453dc174ab

Drolia, R. (2016, January 22). Garbage to gold: Chhattisgarh's Ambikapur to become first Ambikapur to become first dustbin free city . Retrieved from www.timesofindia.indiatimes.com: https://timesofindia.indiatimes.com/city/raipur/Garbage-to-gold-Chhattisgarhs-Ambikapur-to-becomefirst-dustbin-free-city/articleshow/50678420.cms

Ecovative. (2018, June 29). Ecovative partners with CNC exotic mushrooms to reach EU market. Retrieved from www.ecovativedesign.com: https://ecovativedesign.com/press-releases/174

Egerton, S. (2016, August 4). What does the sharing economy mean for a circular economy? Retrieved from www.circulatenews.org: http://circulatenews.org/2016/08/what-does-the-sharing-economy-mean-for-acircular-economy/

FICCI. (2018). Accelerating India's circular economy shift: A half-trillion USD opportunity, future-proofing growth in a resource-scare world. India: Accenture Strategy.

Forbes. (2018, March 06). Meet the members of the three comma club. Retrieved from https://www.forbes.com/billionaires/\#361c446251c7

Growth within a circular economy vision for a competitive Europe. (2015). Ellen MacArthur Foundation.

Guo, B., Geng, Y., Sterr, T., Zhu, Q., \& Liu, Y. (2017). Investigating public awareness on circular economy in western China: A case of Urumqi Midong. Journal of Cleaner Production, 142 (4), 2177-2186.

IKEA Australia. (2018). IKEA Australia People \& Planet Positive 2018, Creating a Circular IKEA. IKEA Australia.

Intelligent assets: Unlocking the circular economy potential. (2016). In Ellen MacArthur Foundation.

Kaplan, S. (2016, January 20). By 2050, there will be more plastic than fish in the world's oceans, study says. Retrieved from https://www.washingtonpost.com/news/morning-mix/wp/ 2016/01/20/by-2050-there-will-bemore-plastic-than-fish-in-the-worlds-oceans-study-says/?noredirect=on\&utm_term=.c42c8984c28e

KPMG. (2017). Future-proof your reverse logistics: Did your supply chain meet the challenge of post-christmas returns? KPMG International.

Lacy, P. (2017, September 14). These 5 disruptive technologies are driving the circular economy. Retrieved from www.weforum.org: https://www.weforum.org/agenda/2017/09/new-tech-sustainable-circular-economy/

Milios, L. (2018). Advancing to a circular economy: three essential ingredients. Sustainable Sci, 13, 861-878.

Mosbergen, D. (2016, August 03). Our consumption of earth's natural resources has more than tripled in 40 years. Retrieved from www.huffingtonpost.com: https://www.huffingtonpost.com/entry/natural-resource-usetripled_us_57a05c3ae4b0693164c273a8

Sandoval, V. P., Garcia, C. J., \& Goenaga, M. O. (2016). Circular economy: An economic and industrial model to acheive the sustainability of society. 22nd International Sustainable Development Research Society Conference. Lisbon: School of Science and Technology, Universidade Nova de Lisboa.

Stahel, W. R. (2010). Performance Economy (2nd ed.). UK: Palgrave Macmillian.

Stahel, W. R. (2016). The circular economy. International Weekly Journal of Science, 531, 435-438.

Stemler, A. (2017). The myth of the sharing economy and its implications for regulating innovation. Emory Law Journal, 67(2), 97-241. 
Stone, S. (2017, November 27). Closing the loop: How a circular economy helps us \#BeatPollution. Retrieved from www.unenvironment.org: https://www.unenvironment.org/news-and-stories/story/closing-loop-howcircular-economy-helps-us-beatpollution

Towards the circular economy: Accelerating the scale-up across global supply chains. (2014). In Ellen MaArthur Foundation. United Kingdom: Ellen MaArthur Foundation.

Ellen MacArthur Foundation. (2015). Towards a circular economy: Business rationale for an accelerated transition. Ellen MacArthur Foundation.

Towards the circular economy vol. 2: Opportunities for the consumer goods sector. (2013). In Ellen Macarthur Foundation. United Kingdom: Ellen MaArthur Foundation.

UN environment. (2016, July 20). Worldwide Extraction of Materials Triples in Four Decades, Intensifying Climate Change and Air Pollution. Retrieved from www.unenvironment.org: https://www.unenvironment.org/news-and-stories/press-release/worldwide-extraction-materials-triplesfour-decades-intensifying

Vaughan, A. (2016, September 27). China tops WHO list for deadly outdoor air pollution. Retrieved from www.theguardian.com: https://www.theguardian.com/environment/2016/sep/27/more-than-milliondied-due-air-pollution-china-one-year

Watts, J. (2018, July 22). Earth's resources consumed in ever greater destructive volumes. Retrieved from www.theguardian.com: https://www.theguardian.com/environment/2018/jul/23/earths-resourcesconsumed-in-ever-greater-destructive-volumes

Webster, K. (2017). The circular economy: A wealth of flows. Ellen Macarthur Foundation.

Wicker, A. (2016, September 1). Fast fashion is creating an environmental crisis. Retrieved from www.newsweek.com: $\quad$ https://www.newsweek.com/2016/09/09/old-clothes-fashion-waste-crisis494824.html

Wijkman, A. (2015, April 15). Circular economy could bring 70 percent cut in carbon emissions by 2030. Retrieved from www.theguardian.com: https://www.theguardian.com/sustainable-business/2015/apr/15/circulareconomy-jobs-climate-carbon-emissions-eu-taxation 